\title{
PENGARUH BRAND IMAGE TERHADAP KEPUTUSAN PEMBELIAN PADA PHOTO CABIN
}

\author{
Rendy Iswanto \\ Ciputra University
}

\begin{abstract}
Abstrak: Brand adalah salah satu inti dalam ilmu desain komunikasi visual. Brand sering sekali terkait dengan keberhasilan dari berbagai macam bisnis, sehingga Brand sering dianggap sebagai jembatan antara ilmu desain komunikasi visual dan bisnis. Penelitian ini bertujuan untuk mengetahui apakah ada pengaruh dari Brand image (yang terdiri dari variabel Corporate Image (X1), User Image (X2), dan Product Image (X3)) terhadap keputusan pembelian pada Photo Cabin (Y). Photo Cabin adalah sebuah usaha di bidang jasa photo corner di Surabaya. Populasi pada penelitian ini adalah konsumen dari Photo Cabin pada tahun 2012 sampai dengan 2015 sebanyak 63 responden. Metode yang digunakan pada penelitian ini adalah analisis regresi linier berganda, $\mathrm{Uji}$ hipotesis dilakukan dengan menggunakan uji F, uji t, koefisien determinasi, dan koefisien korelasi. Hasil dari penelitian ini menyatakan Brand Image memiliki pengaruh yang signifikan terhadap keputusan pembelian terhadap Photo Cabin. Sehingga hal ini menyatakan bahwa brand mempunyai peranan penting terhadap bisnis photo corner dan bisnis-bisnis lain yang serupa. Oleh karena itu para pemilik bisnis photo corner dan praktisi desainer khususnya brand consultant diharapkan memperhatikan desain brand sebagai salah satu hal yang penting menyangkut keberhasilan suatu bisnis.
\end{abstract}

Kata kunci: Brand Image, Corporate Image, User Image, Product Image, Keputusan Pembelian

\begin{abstract}
Brand is one of the core in visual communication design studies, often have a role in a successful many kind of business, hence Brand is considered a bridge between visual communication design studies and business. This study aims to determine the effect of Brand image (which is consists of variable Corporate Image (X1), User Image (X2), and Product Image ( $X 3$ ) on purchase decisions on Photo Cabin ( $Y$ ). Photo Cabin is a business which provide photo corner service in Surabaya. The population in this study is the consumer of the Photo Cabin from 2012 to 2015 which consist of 63 respondents. This study used multiple linear regression
\end{abstract}

Penulis adalah salah satu staf pengajar di Ciputra University, email: rendy.iswanto@ciputra.ac.id 
analysis, hypothesis testing is done using the F test, $t$ test, the coefficient of determination, and the correlation coefficient. The results of this study states that Brand Image has a significant effect on the purchasing decisions of the Photo Cabin. Thus prove that Brand has an important role in photo corner business and to any other similar businesses. Hence photo corner business owners and designer practitioners which is specialize in brand consultant were expected to consider the design of the brand as one of the important things concerning the success of a business.

Keywords: Brand Image, Corporate Image, User Image, Product Image, Buying Decisions

\section{PENDAHULUAN}

Revolusi digital telah menimbulkan banyak sekali perubahan-perubahan disemua aspek kehidupan manusia, terutama pada industri fotografi, dimana jika dulu untuk menikmati hasil dari foto/ mencetak hasil hasil foto, membutuhkan waktu yang cukup lama. Akan tetapi di era digital dewasa ini, hasil dari foto bisa langsung terlihat dari kamera, dan untuk mencetak hasil foto membutuhkan waktu jauh lebih singkat, yakni hanya dalam hitungan detik. Photo corner adalah salah satu bisnis/usaha yang terlahir dari kemajuan digital tersebut. Definisi dari photo corner adalah jasa layanan fotografi yang menggunakan background diletakkan pada salah satu sudut acara pada suatu pesta, dimana acara tersebut bisa berupa acara ulang tahun, acara pernikahan, atau acara launching produk, dll, yang biasanya diperuntukan bagi para tamu undangan dan penyelenggara acara untuk melakukan foto (Sianipar, 2012).

Para tamu yang telah melakukan sesi foto di photo corner, tidak perlu menunggu lama untuk mendapatkan hasil dari fotonya, karena untuk mencetak hasil fotonya hanya memerlukan waktu sekitar 20 detik. Fungsi utama dari jasa photo corner ini adalah berfungsi sebagai souvenir, yang diberikan kepada para tamu undangan sebagai bentuk ucapan terima kasih, sekaligus menjadi 
cinderamata untuk mengenang acara yang bersangkutan. Photo Cabin adalah salah satu perusahaan yang bergerak di bidang jasa photo corner di Surabaya.

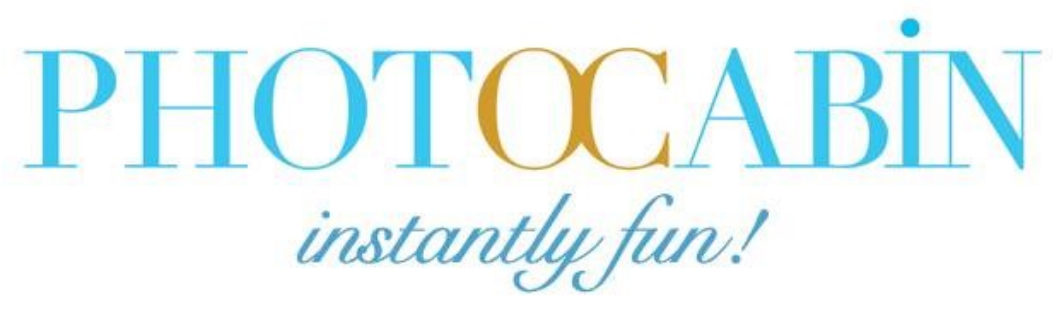

Gambar 1. Logo Photo Cabin

Sumber: dokumentasi pribadi

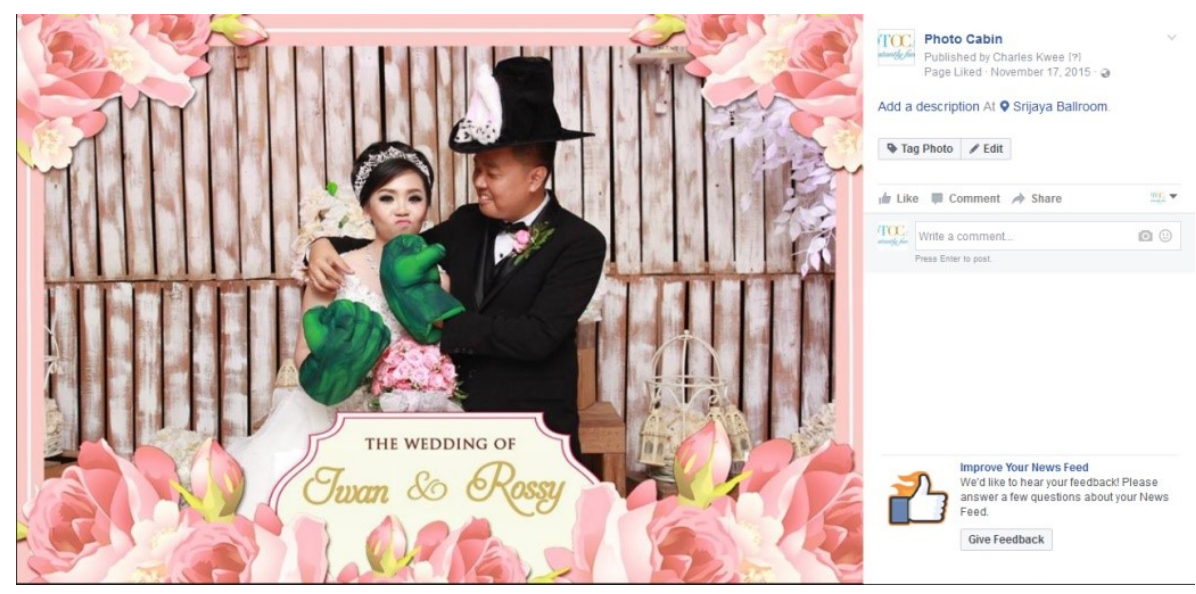

Gambar 2. Contoh hasil foto dari Photo Cabin

Sumber: facebook page Photo Cabin

Rendahnya tingkat barrier level di bidang jasa photo corner ini menjadi ancaman bagi pihak Photo Cabin. Dengan rendahnya entry barrier level menyebabkan mudahnya untuk pemain-pemain baru untuk masuk kedalam usaha di bidang jasa photo corner ini, hal ini menyebabkan banyaknya jumlah pemain usaha photo corner khususnya di kota Surabaya. Tingginya angka persaingan ini adalah masalah yang harus dihadapi oleh Photo Cabin. Ilife adalah salah satu kompetitor utama dari Photo Cabin 


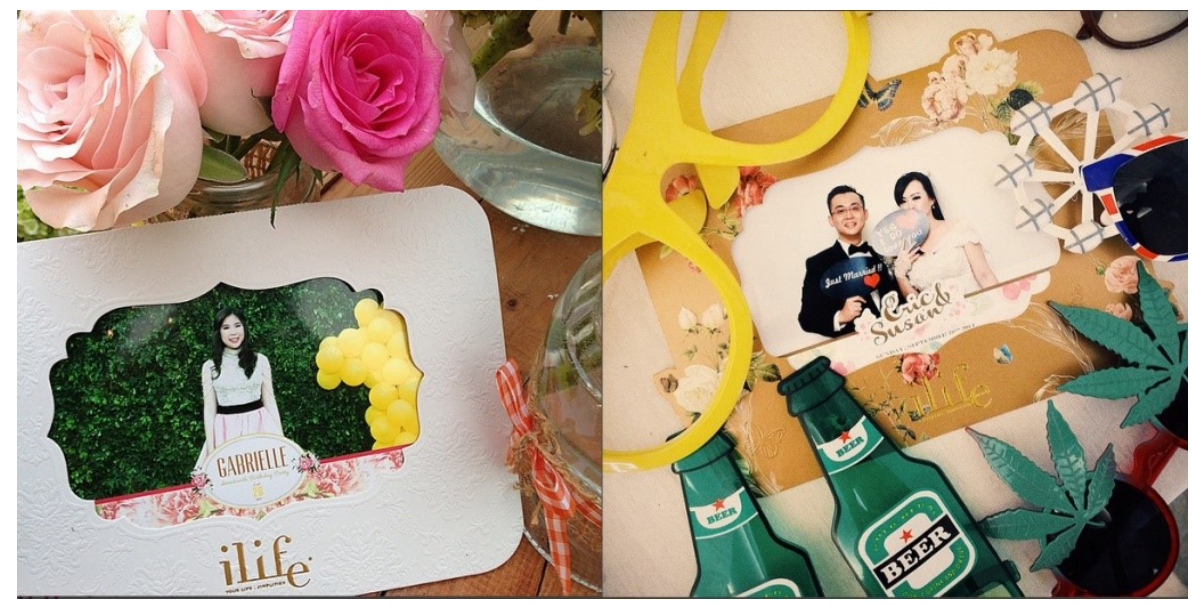

Gambar 3. Hasil foto dari Ilife

Sumber : instagram Ilife

Brand yang merupakan salah satu core ilmu dari bidang desain komunikasi visual, dan sering juga memiliki kaitan yang erat terhadap keberhasilan dari sebuah bisnis, Penelitian ini bertujuan untuk mengetahui seberapa besar pengaruh Brand image terhadap keputusan pembelian pada Photo Cabin sebagai usaha photo corner di Surabaya.

\section{KAJIAN TEORI}

\section{Pengertian Brand Image}

Kotler dan Keller (2009:403) menyatakan bahwa Brand Image merupakan persepsi dari konsumen atau keyakinan, seperti yang tercerminkan oleh asosiasi yang telah tertanamkan ke dalam ingatan para konsumen. Sedangkan definisi Brand Image menurut Rangkuti (2004:244) adalah kumpulan asosiasi yang melekat dan terbentuk di dalam benak konsumen. Definisi brand image menurut Kartajaya (2004:6) adalah sekumpulan sekumpulan dari persepsi konsumen yang terbentuk dari asosiasi dari suatu merek, produk atau jasa yang melekat di benak konsumen. Tjiptono (2005:101) berpendapat bahwa mempunyai brand image 
adalah hal yang sangat vital untuk setiap perusahaan dikarenakan banyaknya keunggulan keunggulan yang didapatkan, seperti persepsi kualitas yang baik, loyalitas brand yang baik sehingga mampu untuk meningkatkan margin laba yang lebih besar dan peluang untuk melakukan perluasan brand (brand extension). Menurut Khasawneh dan Hasouneh (2010: 34), konsumen mengerti akan pentingnya brand image pada waktu melakukan pembelian. Konsumen lebih memilih untuk membeli produk/jasa yang memiliki brand yang baik walaupun harganya lebih mahal jika dibandingkan dengan produk/jasa yang tidak memiliki brand yang baik walaupun harga yang ditawarkan jauh lebih murah, hal ini dikarenakan brand juga merupakan simbol dari status. Nepalia (2011: 113) juga menyimpulkan jika brand sudah terbangun dengan baik, maka nilai produk/jasa juga akan bertambah dalam benak para konsumen.

Para ahli pemasaran menganggap brand sebagai janji dengan konsumen bahkan kualitas produk akan tetap/tidak akan menurun sehingga hal ini menyebabkan naiknya angka penjualan. Berikut indikator brand image menurut Mohammad (2010:61) :

a. Corporate Image (X1): persepsi konsumen terhadap suatu perusahaan seperti kredibilitas, popularitas, jaringan perusahaan, serta para pengguna

b. User Image (X2): persepsi konsumen terhadap penggunaan suatu produk atau jasa, seperti: penggunaan, dan status sosial

c. Produk Image (X3): persepsi konsumen terhadap suatu barang atau jasa seperti manfaat produk atau jasa utk konsumen, atribut produk atau jasa, jaminan dari produk atau jasa

\section{Pengertian Keputusan Pembelian}

Peter dan Olson (2000:162) mendefinisikan keputusan pembelian sebagai integrasi dari kombinasi pengetahuan oleh konsumen untuk mengevaluasi beberapa perilaku alternatif dan memutuskan untuk memilih salah satunya. Kotler 
dan Armstrong (2009:181) berpendapat bahwa pada umumnya konsumen memiliki kecenderungan untuk memilih dari merk yang terkenal atau yang paling disukai. Menurut Oentoro (2012 : 107) Keputusan pembelian adalah kumpulan dari keputusan keputusan yang dimana setiap keputusan tersebut memiliki komponen yang berbeda beda, berikut komponennya :

a. Keputusan mengenai jenis dari produk, konsumen mampu untuk memilih jenis produk tertentu seperti, produk kesehatan, atau produk makanan.

b. Keputusan mengenai bentuk dari produk, menyangkut akan ukuran produk, kualitas produk, desain produk. dll.

c. Keputusan mengenai penjual, keputusan yang menyangkut akan dimana dan siapa yang menjual produk tersebut.

d. Keputusan mengenai merek, dikarenakan setiap merek mempunyai keunikan tersendiri, konsumen akan memilih lebih sesuai dengan kebutuhannya.

e. Keputusan mengenai kuantitas produk, keputusan yang menyangkut akan jumlah produk

f. Keputusan mengenai waktu pembelian, berhubungan kapan konsumen biasanya membeli suatu produk.

g. Keputusan mengenai cara pembayaran, keputusan yang menyangkut akan bagaimana cara pelunasan transaksi terhadap produk tersebut, seperti cicilan, atau tunai.

\section{Hubungan antara Brand Image dengan Keputusan Pembelian}

Schiffman dan Kanuk (2008:173) juga menyatakan jika konsumen tidak memiliki informasi/pengalaman tentang suatu brand/merek, produk atau jasa, maka mereka akan cenderung untuk lebih mempercayai brand/merek yang sudah terkenal atau disukai banyak orang. Keputusan pembelian sangat erat hubungannya dengan perilaku konsumen, jika suatu brand/merek, produk atau 
jasa dapat memenuhi kebutuan konsumen, maka konsumen tersebut akan melakukan pembelian ulang kepada brand/merek, produk atau jasa tersebut. Ogilvy dan Mather pada Andreani dkk (2012:65) mengatakan bahwa brand mempunyai peran yang sangat penting karena mampu membedakan suatu perusahaan/produk dengan perusahaan/produk yang lain. Brand yang kuat juga mampu untuk membuat konsumen melakukan pembelian berulang. Hal ini di support juga pada penelitian Lin dkk (2007:122), dimana dinyatakan bahwa konsumen bisa mengenali, mengevaluasi, dan memperoleh kepuasan dari diferensiasi produk atau jasa tersebut. Menurut Kotler (2004:90) brand/merek dapat mencerminkan kualitas pelayanan, manfaat, bahkan citra/image yang didapat oleh konsumen setelah menggunakan produk atau jasa tersebut. Dari penjelasan-penjelasan tersebut maka didapatkan brand/merek adalah salah satu keputusan strategis yang diperhatikan dengan baik oleh suatu perusahaan.

\section{KERANGKA KONSEP PEMIKIRAN}

Seperti yang dijelaskan pada pendahuluan dan tinjauan pustaka maka didapat dua variabel dalam penelitian ini, yakni variabel tak terikat $(\mathrm{X})$ : brand image, dan variabel terikat $(\mathrm{Y})$ : keputusan pembelian, dan Hubungan antara variabel variabel tersebut bisa dilihat pada gambar dibawah ini :

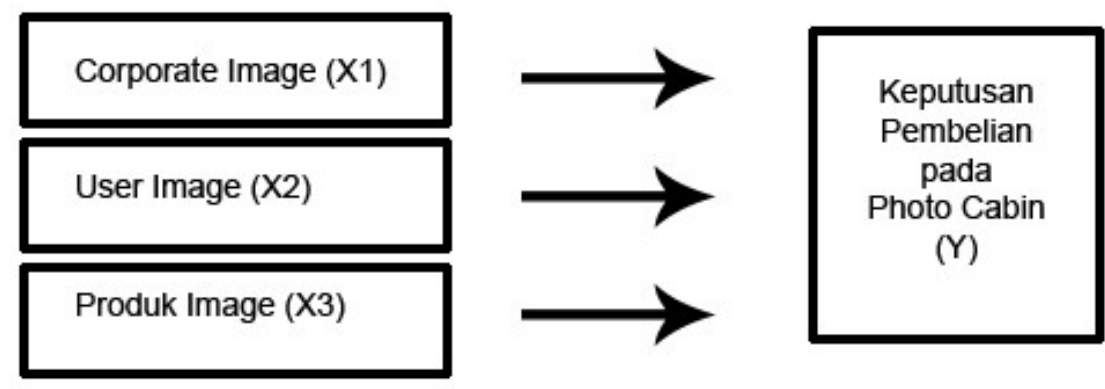

Gambar 4. bagan hubungan antar variabel 
Agar mendapatkan pengarahan dan pedoman yang jelas dalam melakukan penelitian maka diajukan hipotesis sebagai berikut :

a. H1 Corporate Image mempunyai pengaruh positif terhadap keputusan pembelian jasa pada Photo Cabin

b. H2 User Image mempunyai pengaruh positif terhadap keputusan pembelian jasa pada Photo Cabin

c. H3 Produk Image mempunyai pengaruh positif terhadap keputusan pembelian jasa pada Photo Cabin

d. H4 : Brand mempunyai pengaruh positif terhadap keputusan pembelian jasa pada Photo Cabin

\section{METODE PENELITIAN}

Untuk mengetahui seberapa besar pengaruh brand image pada keputusan pembelian pada Photo Cabin maka penelitian ini menggunakan metode kuantitatif. Populasi penelitian ini adalah konsumen dari photo Cabin pada tahun 2012 sampai dengan 2015 sebanyak 63 responden, mengingat jumlah responden yang tidak lebih dari 100 oleh karena itu seluruh populasi digunakan sebagai responden dan tidak menggunakan teknik sampling. Untuk mengumpulkan data penelitian ini menggunakan kuesioner dengan pertanyaan yang bersifat tertutup, dan menggunakan skala Likert. Untuk analisa data menggunakan analisis sebagai berikut: Analisis Regresi Linier Berganda, Uji t, Uji F, koefisien korelasi dan koefisien determinasi. 


\section{HASIL DAN DISKUSI}

\section{Analisis Deskriptif}

\section{Corporate Image (X1)}

Berikut adalah deskripsi jawaban responden pada variabel Corporate Image:

Tabel 1. Deskripsi Jawaban Responden Pada Variabel Corporate Image

\begin{tabular}{|c|c|c|c|c|c|c|c|c|c|c|c|c|}
\hline \multirow{3}{*}{ Indikator } & \multicolumn{10}{|c|}{ Frekuensi Skor Jawaban } & \multirow{3}{*}{$\begin{array}{l}\text { Rata- } \\
\text { rata }\end{array}$} & \multirow{3}{*}{$\begin{array}{c}\text { Std. } \\
\text { Devias }\end{array}$} \\
\hline & \multicolumn{2}{|c|}{1} & \multicolumn{2}{|c|}{2} & \multicolumn{2}{|c|}{3} & \multicolumn{2}{|c|}{4} & \multicolumn{2}{|c|}{5} & & \\
\hline & $\mathrm{F}$ & $\%$ & $\mathrm{~F}$ & $\%$ & $\mathrm{~F}$ & $\%$ & $\mathrm{~F}$ & $\%$ & $\mathrm{~F}$ & $\%$ & & \\
\hline $\mathrm{X} 1.1$ & 0 & 0 & 7 & 11.1 & 18 & 28.6 & 26 & 41.3 & 12 & 19.0 & 3.68 & 0.913 \\
\hline $\mathrm{X} 1.2$ & 0 & 0 & 3 & 4.8 & 16 & 25.4 & 30 & 47.6 & 14 & 22.2 & 3.87 & 0.813 \\
\hline $\mathrm{X} 1.3$ & 0 & 0 & 4 & 6.3 & 25 & 39.7 & 24 & 38.1 & 10 & 15.9 & 3.63 & 0.829 \\
\hline $\mathrm{X} 1.4$ & 0 & 0 & 6 & 9.5 & 26 & 41.3 & 25 & 39.7 & 6 & 9.5 & 3.49 & 0.801 \\
\hline & & & & & & & & & & & 3.67 & \\
\hline
\end{tabular}

Sumber: Data Diolah

Tabel 1 menunjukkan bahwa secara keseluruhan, persepsi konsumen Photo Cabin mengenai Corporate Image yaitu sebesar 3.67, dimana nilai tersebut mendekati skor 4 pada skala likert penelitian. Hal ini menunjukkan Corporate Image dari Photo Cabin yang dipersepsikan baik oleh konsumen. Persepsi tertinggi mengenai Corporate Image yaitu terletak pada Logo Photo Cabin dan tagline "Instantly Fun" yang dapat dengan mudah diingat dan dimaknai oleh konsumen, yaitu ditunjukkan dengan nilai rata-rata sebesar 3.87 pada indikator X1.1, sedangkan persepsi terendah mengenai Corporate Image dirasakan oleh konsumen Photo Cabin terletak pada keluhan dan saran yang ditanggapi dengan baik oleh pihak Photo Cabin, yaitu ditunjukkan dengan rata-rata sebesar 3.49 pada indikator X1.4. Standar deviasi menunjukkan keragaman data jawaban di masingmasing indikator pernyataan kuisioner. Diketahui bahwa standar deviasi terendah yaitu sebesar 0.801 pada indikator X1.4. Hal ini menunjukkan bahwa responden 
memiliki persepsi yang paling homogen mengenai keluhan dan saran yang ditanggapi dengan baik oleh pihak Photo Cabin.

\section{User Image (X2)}

Berikut adalah deskripsi jawaban responden pada variabel User Image:

Tabel 2. Deskripsi Jawaban Responden Pada Variabel User Image

\begin{tabular}{|c|c|c|c|c|c|c|c|c|c|c|c|c|}
\hline \multirow{3}{*}{ Indikator } & \multicolumn{10}{|c|}{ Frekuensi Skor Jawaban } & \multirow{3}{*}{$\begin{array}{l}\text { Rata- } \\
\text { rata }\end{array}$} & \multirow{3}{*}{$\begin{array}{c}\text { Std. } \\
\text { Deviasi }\end{array}$} \\
\hline & \multicolumn{2}{|c|}{1} & \multicolumn{2}{|c|}{2} & \multicolumn{2}{|c|}{3} & \multicolumn{2}{|c|}{4} & \multicolumn{2}{|c|}{5} & & \\
\hline & $\mathrm{F}$ & $\%$ & $\mathrm{~F}$ & $\%$ & $\mathrm{~F}$ & $\%$ & $\mathrm{~F}$ & $\%$ & $\mathrm{~F}$ & $\%$ & & \\
\hline $\mathrm{X} 2.1$ & 0 & 0 & 6 & 9.5 & 18 & 28.6 & 23 & 36.5 & 16 & 25.4 & 3.78 & 0.941 \\
\hline $\mathrm{X} 2.2$ & 0 & 0 & 5 & 7.9 & 21 & 33.3 & 23 & 36.5 & 14 & 22.2 & 3.73 & 0.902 \\
\hline $\mathrm{X} 2.3$ & 2 & 3.2 & 5 & 7.9 & 22 & 34.9 & 25 & 39.7 & 9 & 14.3 & 3.54 & 0.947 \\
\hline \multicolumn{11}{|c|}{ User Image } & 3.68 & \\
\hline
\end{tabular}

Sumber: Data Diolah

Tabel 2 menunjukkan bahwa secara keseluruhan, persepsi konsumen mengenai User Image di Photo Cabin yaitu sebesar 3.68, dimana nilai tersebut mendekati skor 4 pada skala likert penelitian. Hal ini menunjukkan User Image dari Photo Cabin yang dipersepsikan baik oleh koinsumen. Persepsi tertinggi mengenai User Image yaitu terletak pada kesesuaian jasa Photo Cabin dengan harapan konsumen, yaitu ditunjukkan dengan nilai rata-rata sebesar 3.78 pada indikator X2.1, sedangkan persepsi terendah mengenai User Image dirasakan oleh konsumen Photo Cabin terletak pada kualitas jasa dari Photo Cabin yang melebihi jasa photo corner yang lain, yaitu ditunjukkan dengan rata-rata sebesar 3.54 pada indikator X2.3. Diketahui bahwa standar deviasi terendah yaitu sebesar 0.902 pada indikator X2.2. Hal ini menunjukkan bahwa responden memiliki persepsi yang paling homogen pada kebutuhan atas photo booth/photo corner yang dapat terpenuhi saat menggunakan jasa Photo Cabin. 


\section{Product Image (X3)}

Berikut adalah deskripsi jawaban responden pada variabel Product Image:

Tabel 3. Deskripsi Jawaban Responden Pada Variabel Product Image

\begin{tabular}{|c|c|c|c|c|c|c|c|c|c|c|c|c|}
\hline \multirow{3}{*}{ Indikator } & \multicolumn{10}{|c|}{ Frekuensi Skor Jawaban } & \multirow{3}{*}{$\begin{array}{l}\text { Rata- } \\
\text { rata }\end{array}$} & \multirow{3}{*}{$\begin{array}{c}\text { Std. } \\
\text { Devias }\end{array}$} \\
\hline & \multicolumn{2}{|c|}{1} & \multicolumn{2}{|c|}{2} & \multicolumn{2}{|c|}{3} & \multicolumn{2}{|c|}{4} & \multicolumn{2}{|c|}{5} & & \\
\hline & $\mathrm{F}$ & $\%$ & $\mathrm{~F}$ & $\%$ & $\mathrm{~F}$ & $\%$ & $\mathrm{~F}$ & $\%$ & $\mathrm{~F}$ & $\%$ & & \\
\hline X3.1 & 0 & 0 & 1 & 1.6 & 16 & 25.4 & 28 & 44.4 & 18 & 28.6 & 4.00 & 0.783 \\
\hline $\mathrm{X} 3.2$ & 0 & 0 & 1 & 1.6 & 17 & 27.0 & 28 & 44.4 & 17 & 27.0 & 3.97 & 0.782 \\
\hline $\mathrm{X} 3.3$ & 0 & 0 & 1 & 1.6 & 18 & 28.6 & 39 & 61.9 & 5 & 7.9 & 3.76 & 0.615 \\
\hline $\mathrm{X} 3.4$ & 0 & 0 & 1 & 1.6 & 15 & 23.8 & 39 & 61.9 & 8 & 12.7 & 3.86 & 0.644 \\
\hline $\mathrm{X} 3.5$ & 0 & 0 & 1 & 1.6 & 23 & 36.5 & 34 & 54.0 & 5 & 7.9 & 3.68 & 0.643 \\
\hline \multicolumn{11}{|c|}{ Product Image } & 3.85 & \\
\hline
\end{tabular}

Sumber: Data Diolah

Tabel 3 menunjukkan bahwa secara keseluruhan, persepsi konsumen Photo Cabin mengenai Product Image yaitu sebesar 3.85, dimana nilai tersebut mendekati skor 4 pada skala likert penelitian. Hal ini menunjukkan Product Image dari Photo Cabin yang dipersepsikan baik oleh konsumen. Persepsi tertinggi mengenai Product Image yaitu terletak pada logo Photo Cabin pada desain frame yang dapat memudahkan konsumen untuk mengingatkan akan jasa Photo Cabin, yaitu ditunjukkan dengan nilai rata-rata sebesar 4.00 pada indikator X3.1, sedangkan persepsi terendah mengenai Product Image dirasakan oleh konsumen Photo Cabin terletak pada kepuasan akan harga paket yang ditawarkan oleh Photo Cabin, yaitu ditunjukkan dengan rata-rata sebesar 3.68 pada indikator X3.5. Standar deviasi terendah yaitu sebesar 0.615 pada indikator X3.3. Hal ini menunjukkan bahwa responden memiliki persepsi yang paling homogen mengenai kepuasan pada hasil foto dari Photo Cabin. 


\section{Keputusan Pembelian (Y)}

Berikut adalah deskripsi jawaban responden pada variabel Keputusan Pembelian:

Tabel 4. Deskripsi Jawaban Responden Pada Variabel Keputusan Pembelian

\begin{tabular}{|c|c|c|c|c|c|c|c|c|c|c|c|c|}
\hline \multirow{3}{*}{ Indikator } & \multicolumn{10}{|c|}{ Frekuensi Skor Jawaban } & \multirow{3}{*}{$\begin{array}{l}\text { Rata- } \\
\text { rata }\end{array}$} & \multirow{3}{*}{$\begin{array}{c}\text { Std. } \\
\text { Deviasi }\end{array}$} \\
\hline & \multicolumn{2}{|c|}{1} & \multicolumn{2}{|c|}{2} & \multicolumn{2}{|c|}{3} & \multicolumn{2}{|c|}{4} & \multicolumn{2}{|c|}{5} & & \\
\hline & $\mathrm{F}$ & $\%$ & $\mathrm{~F}$ & $\%$ & $\mathrm{~F}$ & $\%$ & $\mathrm{~F}$ & $\%$ & $\mathrm{~F}$ & $\%$ & & \\
\hline Y1.1 & 0 & 0 & 1 & 1.6 & 17 & 27.0 & 31 & 49.2 & 14 & 22.2 & 3.92 & 0.747 \\
\hline Y1.2 & 0 & 0 & 4 & 6.3 & 17 & 27.0 & 34 & 54.0 & 8 & 12.7 & 3.73 & 0.766 \\
\hline Y1.3 & 0 & 0 & 3 & 4.8 & 24 & 38.1 & 27 & 42.9 & 9 & 14.3 & 3.67 & 0.783 \\
\hline Y1.4 & 0 & 0 & 1 & 1.6 & 22 & 34.9 & 24 & 38.1 & 16 & 25.4 & 3.87 & 0.813 \\
\hline Y1.5 & 0 & 0 & 1 & 1.6 & 21 & 33.3 & 33 & 52.4 & 8 & 12.7 & 3.76 & 0.689 \\
\hline Y1.6 & 0 & 0 & 4 & 6.3 & 19 & 30.2 & 33 & 52.4 & 7 & 11.1 & 3.68 & 0.758 \\
\hline Y1.7 & 1 & 1.6 & 2 & 3.2 & 17 & 27.0 & 36 & 57.1 & 7 & 11.1 & 3.73 & 0.766 \\
\hline \multicolumn{11}{|c|}{ Keputusan Pembelian } & 3.77 & \\
\hline
\end{tabular}

Sumber: Data Diolah

Tabel 4 menunjukkan bahwa secara keseluruhan, persepsi konsumen mengenai Keputusan pembelian di Photo Cabin yaitu sebesar 3.77, dimana nilai tersebut mendekati skor 4 pada skala likert penelitian. Hal ini menunjukkan keputusan pembelian konsumen Photo Cabin dapat dikatakan tinggi. Persepsi tertinggi mengenai Keputusan pembelian yaitu terletak pada pemilihan Photo Cabin dikarenakan adanya keperluan pada jasa photo corner/photo booth, yaitu ditunjukkan dengan nilai rata-rata sebesar 3.92 pada indikator Y1.1, sedangkan persepsi terendah mengenai Keputusan pembelian dirasakan oleh konsumen Photo Cabin terletak pada pemilihan Photo Cabin dikarenakan adanya rekomendasi dari orang lain, yaitu ditunjukkan dengan rata-rata sebesar 3.67 pada indikator Y1.3. Diketahui bahwa standar deviasi terendah yaitu sebesar 0.689 pada indikator Y1.5. Hal ini menunjukkan bahwa responden memiliki persepsi yang 
paling homogen pada cara pembayaran pada Photo Cabin yang tidak menyusahkan konsumen.

\section{Analisis Regresi Linear Berganda}

Analisis regresi linier berganda dilakukan untuk mengetahui pengaruh variabel Brand image yang terdiri dari Corporate Image (X1), User Image (X2), Product Image (X3), terhadap Keputusan Pembelian (Y) dari konsumen Photo Cabin. Hasil analisis regresi dengan SPSS adalah sebagai berikut:

Tabel 5. Hasi Analisis Regresi Linier Berganda

Coefficients

\begin{tabular}{|c|c|c|c|c|c|c|c|c|}
\hline \multirow{2}{*}{\multicolumn{2}{|c|}{ Model }} & \multicolumn{2}{|c|}{$\begin{array}{l}\text { Unstandardized } \\
\text { Coefficients }\end{array}$} & \multirow{2}{*}{$\begin{array}{c}\begin{array}{c}\text { Standardized } \\
\text { Coefficients }\end{array} \\
\text { Beta } \\
\end{array}$} & \multirow[b]{2}{*}{$\mathrm{t}$} & \multirow[b]{2}{*}{ Sig. } & \multicolumn{2}{|c|}{ Collinearity Statistics } \\
\hline & & $\mathrm{B}$ & Std. Error & & & & Tolerance & VIF \\
\hline \multirow[t]{4}{*}{1} & (Constant) & .183 & .313 & & .584 & .581 & & \\
\hline & $\mathrm{X} 1$ & .198 & .070 & .241 & 2.820 & .007 & .648 & 1.542 \\
\hline & $x 2$ & .250 & .060 & .351 & 4.165 & .000 & .685 & 1.504 \\
\hline & $\times 3$ & .502 & .100 & .434 & 5.015 & .000 & .630 & 1.587 \\
\hline \multicolumn{2}{|c|}{ R: } & 0,850 & & & & & & \\
\hline \multicolumn{2}{|c|}{ R square : } & 0,722 & & & & & & \\
\hline \multicolumn{2}{|c|}{$f:$} & 51.012 & & & & & & \\
\hline \multicolumn{2}{|c|}{ f sig : } & 0,000 & & & & & & \\
\hline
\end{tabular}

Sumber: Data Diolah

Berdasarkan hasil analisis pada Tabel 5 maka persamaan regresi yang didapatkan adalah:

$$
\hat{Y}=0,183+0,198 X_{1}+0,250 X_{2}+0,502 X_{3}
$$

Konstanta sebesar 0.183 menyatakan apabila Corporate Image (X1), User Image (X2), dan Product Image (X3) bernilai 0 atau tidak memberikan pengaruh, maka Keputusan Pembelian dari konsumen Photo Cabin adalah 0.183 satuan.

Nilai koefisien regresi dari variabel Corporate Image (X1) adalah 0.198. Tanda positif pada koefisien regresi melambangkan hubungan yang searah antara Corporate Image dengan Keputusan Pembelian, sehingga jika Corporate Image 
semakin baik ,maka keputusan pembelian dari konsumen akan meningkat 0.198 satuan, dengan asumsi User Image (X2), dan Product Image (X3) konstan.

Nilai koefisien regresi dari variabel User Image (X2) adalah 0.250. Tanda positif pada koefisien regresi melambangkan hubungan yang searah antara User Image dengan Keputusan Pembelian, sehingga jika User Image semakin baik, maka keputusan pembelian dari konsumen akan meningkat sebesar 0.250 satuan, dengan asumsi Corporate Image (X1) dan Product Image (X3) konstan.

Nilai koefisien regresi dari variabel Product Image (X3) adalah 0.502. Tanda positif pada koefisien regresi melambangkan hubungan yang searah antara Product Image dan Keputusan Pembelian, sehingga jika Product Image semakin baik, maka keputusan pembelian dari konsumen akan meningkat sebesar 0.502 satuan, dengan asumsi Corporate Image (X1) dan User Image (X2) konstan.

\section{Koefisien Determinasi dan Koefisien Korelasi}

Tabel 5 menunjukkan nilai koefisien determinasi adalah sebesar 0.722 . Sehingga dapat disimpulkan bahwa variabel Corporate Image (X1), User Image (X2), dan Product Image (X3) memiliki pengaruh sebesar 72.2\% terhadap variabel Keputusan Pembelian konsumen Photo Cabin (Y). Tabel 5 menunjukkan nilai Koefisien korelasi adalah sebesar 0.850, sehingga dapat disimpulkan bahwa hubungan antara variabel Corporate Image (X1), User Image (X2), dan Product Image (X3) terhadap Keputusan Pembelian konsumen Photo Cabin (Y) adalah sangat tinggi.

Uji F

Tabel 5 menunjukkan hasil dari uji $\mathrm{F}$ dimana nilai dari signifikansi yang dihasilkan adalah sebesar 0.000 sehingga dapat disimpulkan bahwa variabel Corporate Image (X1), User Image (X2), dan Product Image (X3) mempunya pengaruh secara simultan terhadap variabel Keputusan Pembelian (Y). Dari hasil 
ini maka hipotesis penelitian ( $\mathrm{H} 4$ ) yang menyebutkan bahwa variabel Brand Image secara memiliki pengaruh signifikan terhadap Keputusan Pembelian, adalah benar Uji t

Tabel 5 menunjukkan pengujian pengaruh variabel Corporate Image (X1) terhadap keputusan pembelian (Y) menghasilkan t hitung sebesar 2.820 dengan nilai signifikansi sebesar 0.007 . Sehingga dapat disimpulkan bahwa Corporate Image mempunyai pengaruh yang signifikan terhadap keputusan pembelian konsumen Photo Cabin secara parsial. Oleh karena itu, hipotesis (H1) yang menduga terdapat pengaruh secara signifikan dari variabel Corporate Image terhadap keputusan pembelian, adalah benar.

Tabel 5 menunjukkan pengujian pengaruh variabel User Image (X2) terhadap keputusan pembelian (Y) menghasilkan t hitung sebesar 4.165 dengan nilai signifikansi sebesar 0.000. Sehingga dapat disimpulkan bahwa User Image mempunyai pengaruh signifikan terhadap keputusan pembelian dari konsumen Photo Cabin secara parsial. Oleh karena itu, hipotesis $(\mathrm{H} 2)$ yang menduga terdapat pengaruh secara signifikan dari variabel User Image terhadap keputusan pembelian, adalah benar.

Tabel 5 menunjukkan pengujian pengaruh variabel Product Image (X3) terhadap keputusan pembelian menghasilkan t hitung sebesar 5.015 dengan nilai signifikansi sebesar 0.000. Sehingga dapat disimpulkan bahwa Product Image mempunyai pengaruh signifikan terhadap keputusan pembelian konsumen Photo Cabin secara parsial. Oleh karena itu, hipotesis $(\mathrm{H} 3)$ yang menduga terdapat pengaruh secara signifikan dari variabel Product Image terhadap keputusan pembelian, adalah benar.

\section{KESIMPULAN DAN SARAN}

Brand adalah salah satu inti dalam ilmu desain komunikasi visual, sering sekali menjadi kunci keberhasilan dari berbagai macam bisnis. Oleh karena itu 
brand dianggap sebagai jembatan antara ilmu desain komunikasi visual dan bisnis. Penelitian ini bertujuan untuk mengetahui pengaruh Brand image yang terdiri dari Corporate Image (X1), User Image (X2), Produk Image (X3) terhadap keputusan pembelian (Y) pada Photo Cabin sebagai usaha photo corner di Surabaya. Dalam hasil analisa diatas maka dapat ditarik kesimpulan sebagai berikut:

1. Sesuai dengan hipotesis $\mathrm{H} 1, \mathrm{H} 2$ dan $\mathrm{H} 3$, yang menyatakan bahwa variabel Corporate Image (X1), User Image (X2), dan Product Image (X3) terbukti memiliki pengaruh yang signifikan terhadap keputusan pembelian pada Photo Cabin $(\mathrm{Y})$ secara parsial.

2. Sesuai dengan hipotesis $\mathrm{H} 4$, yang menyatakan bahwa variabel Corporate Image (X1), User Image (X2), dan Product Image (X3) terbukti memiliki pengaruh yang signifikan terhadap keputusan pembelian pada Photo Cabin (Y) secara keseluruhan.

Dari kesimpulan diatas dapat dinyatakan bahwa Brand image terbukti memiliki pengaruh signifikan terhadap keputusan pembelian. Sehingga membuktikan bahwa Brand sebagai inti dalam ilmu desain komunikasi visual ternyata berperan penting juga dalam bisnis photo corner. Oleh karena itu perancangan brand dianggap penting untuk menarik konsumen. Hal ini juga dapat dilihat dari tabel 1 dimana menunjukkan Persepsi tertinggi mengenai Corporate Image yaitu terletak pada Logo Photo Cabin dan tagline "Instantly Fun" yang dapat dengan mudah diingat dan dimaknai oleh konsumen, yaitu ditunjukkan dengan nilai rata-rata sebesar 3.87 pada indikator X1.1. Disini menyatakan bahwa perancangan logo dan tagline yang menarik sangat berperan terhadap keputusan pembelian.

Saran untuk pihak Photo Cabin, selain untuk memperhatikan kualitas layanan, agar mampu juga untuk memperhatikan dan mempertahankan desain yang menarik dalam pernik pernik brand Photo Cabin seperti, desain frame, desain 
template foto dan berbagai materi promosi lainnya dan juga agar tetap mampu untuk mengkomunikasikan tagline "Instantly Fun" baik melalui desain dari pernik pernik dan berbagai materi promosi Photo Cabin itu sendiri, asesoris foto, maupun dari hasil foto/produk dan jasa/service Photo Cabin pada acara yang berlangsung, sehingga para klien dan tamu benar benar merasakan tagline "Instantly Fun" dan mampu untuk mengasosiasikan tagline tersebut terhadap Photo Cabin itu sendiri.

Saran untuk pelaku bisnis photo corner yang lain agar juga memperhatikan perancangan brand dari usaha mereka, selain dari kualitas layanan dan produk yang dihasilkan, karena terbukti brand memiliki peranan penting terhadap keputusan pembelian pada usaha photo corner juga melalui penelitian ini. Dan saran untuk penelitian di kemudian hari agar dapat menggunakan variabel lain dari penelitian ini, agar dapat memperoleh informasi yang lebih terhadap variabel keputusan pembelian terutama dalam bisnis photo corner.

\section{DAFTAR PUSTAKA}

Andreani, et al., 2012. The Impact of Brand Image towards Loyalty with Satisfaction as A Mediator in McDonald's. Jurnal manajemen dan kewirausahaan, Vol.14, No.1, Maret 2012: 64-71.

Kartajaya, H., 2004. Mark Plus on Strategy. Jakarta: PT. Gramedia Pustaka Utama. Khasawneh, K. dan Hasouneh, A.B.I., 2010. The effect of familiar brand names on consumer behaviour: A Jordanian Perspective. International Research Journal of Finance and Economics, 43: 33-57.

Kotler, P., 2004. Manajemen Pemasaran Jilid II Edisi Milenium. Jakarta: PT. Prenhalindo.

Kotler, P. dan Keller, K.L., 2009. Manajemen Pemasaran. Jilid 1. Edisi ke 13. Diterjemahkan oleh Bob Sabran. Jakarta: Erlangga. 
Lin, Nan-Hong dan Bih-Syah Lin. 2007. The Effect of Brand Image and Product Knowledge on Purchase Intention Moderated by Price Discount. Journal of International Managements Studies, 121132.

Tambrin, M., 2010. Pengaruh Brand Image Terhadap Pelanggan Kartu Simpati Terhadap Kepuasan Mahasiswa Universitas Trunojoyo Madura. Jurnal Studi Manajemen. Vol 4 No.1 April 2010.

Nepalia. 2011. Brand management and its impact on consumer buying behavior. International Referred Research Journal, 1(17): 113-114.

Oentoro, D., 2010. Manajemen Pemasaran Modern. Yogyakarta: LaksBang Pressindo.

Peter, J.P., dan Jerry C. O., 2000. Consumer Behaviour. Perilaku konsumen dan Strategi Pemasaran. Jilid 2. Edisi 4. Diterjemahkan oleh Damos Sihombing. Jakarta: Erlangga.

Rangkuti, F., 2002. The power of Brand. Jakarta: PT Gramedia Pustaka Utama.

Schiffman, L., dan Kanuk, L.L., 2008. Perilaku Konsumen. Edisi Ketujuh. Diterjemahkan oleh: Zoelkifli Kasip. Jakarta: Indeks.

Sianipar, M. (2012) "Jasa Photobooth Profesional di Pekanbaru". Tersedia di: http://www.magiccorner.com/index.php?option=com_content\&view=article\&id= 77:jasa-photobooth profesional-di\%20pekanbaru\&catid=35: artikel\&Itemid=156 (diakses tanggal 31 Januari 2016).

Tjiptono, F., 2005. Brand Management \& Strategi. Yogyakarta: Andi. 